\title{
University English Teachers' Identity in Minority Area: A Case Study of a Trilingual Teacher in China
}

\author{
Baiyinna Wu (Corresponding author) \\ Foreign Languages Institute, Inner Mongolia Normal University \\ 81 Zhao Wu Da Road, Sai Han District, Huhhot 010022, China \\ Tel: 86-471-439-3351_E-mail: byntnwu@gmail.com
}

Wurenbilige

Foreign Languages Institute, Inner Mongolia Normal University

81 Zhao Wu Da Road, Sai Han District, Huhhot 010022, China

Tel: 86-471-439-3351 E-mail: wurenbilige730051@163.com

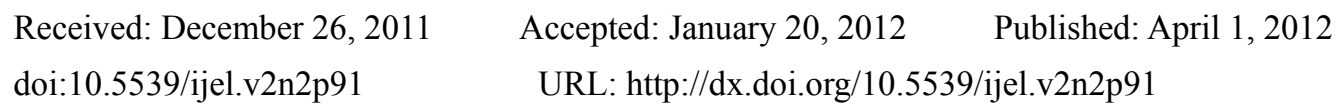

\begin{abstract}
Teacher identity is a very hot topic attracting lots of researchers' attention in teaching and teacher development since it treats teachers as whole persons in and across social and contexts who continually reconstruct their views of themselves in relation to others, workplace characteristics, professional purposes, and cultures of teaching. As one aspect of teacher identity, minority teachers' identity has begun to gain great interest in this area. The present study investigates Mongolian English university teachers' identity formation in minority area. The study addressed the following three research questions: What is the identity of Mongolian English teachers at university? How do Mongolian English teachers at university perceive their identity? What are the factors influencing their identity formation? The findings suggest that Mongolian English teacher's identity is complex and multifaceted, which is influenced by various factors, among which the subject's learning experiences as being a third language learner play very crucial role in constructing her identity.
\end{abstract}

Keywords: English teacher, Teacher identity, Language use, Learning experience

\section{Introduction}

In recent years, people have begun to realize that the essence of educational reform is teachers and teachers' development is crucial to the teaching reform. Fred (2004) pointed out that external and internal factors of teachers' quality structure interact with and influence each other to change teachers. The external factors include environment, ability, which can be easily changed, and the internal factors comprise beliefs, identity and mission, which are very difficult to be changed; however, changing teachers depend on changing teachers' beliefs and identities. Therefore, teacher education should not rest on changing the teachers' behavior and ability only; teacher identity should be the focus of the teacher education.

Classroom is the site in which teachers spend most of their working hours interacting with students, and by observing interaction between teachers and students, people can understand how teacher identity is constructed. However, for a long time, there have been few classroom-based researches, ignoring the teachers' contributions to the classroom practices. We need to understand the things taking place inside the classroom, and teachers should deserve the focus of the attention from the researchers. It is certain that in the teaching, teachers' beliefs, attitudes and knowledge are playing significant roles; however, teachers' identity can be the determining element for how the teaching is carried out (Johnson, 1992), which influences teaching and learning. In the on-going process of teacher identity construction, the relations with the students in the narrow sense and with the contexts where the teacher works and lives in the broader sense are vital. Therefore, it is believed that it is significant to understand Mongolian teachers of English if we want to know how third language teaching and learning is going on; it is necessary to understand who the Mongolian English teachers are. In particular, the present study 
investigates what identity of Mongolian teachers of English at university is; how Mongolian teachers of English at university perceive their identity; what factors influencing their identity formation are from the perspectives of cultural, social contexts.

\section{Literature review}

\subsection{Understanding of some basic concepts}

It is difficult to define identity since it is multi-dimensional concept interpreted variously by different people. Reviewing the relevant literature, it is not hard to uncover the different understandings of the concept, identity by scholars in the fields of psychology, philosophy, anthropology, sociology and education. According to Psychologist Erikson (1968), identity is something that develops during one's whole life. Mead (1934) defines the concept of identity relating it to the concept of self, arguing that people's self is shaped and constructed rather than perceived as being certain features and common characteristics. However, the scholars have the consensus that in general, identity is the knowledge of who I am, what kind of person I am, which is not stable and fixed; on the contrary, it is dynamic and continuously develops through one's whole life time and is reinterpreted and reshaped in the process of interacting with the social and cultural community in which he lives.

As identity is a vague concept and defined differently, providing a clear definition to teachers' identity is also a hard task for the researchers since it is dynamic and changes over time. The development of teacher's identity is a continuing and dynamic process. As suggested, teacher identity is continually being shaped and reshaped as they develop in their whole process of teaching career and through interaction with others such as the colleagues and students (Franzak, 2002).

\subsection{Relevant studies}

As teacher education and teacher development become a major issue, teacher identity has attracted many scholars' attention at abroad. Beauchamp \& Thomas (2009) summarized the issues related to teacher identity in teacher development, and special attention is given to pre-service teacher identity and new practitioners, highlighting the significance of understanding those relevant issues for programs of teacher education. Flores \& Day (2006) explored how the new teachers' identities were constructed and reconstructed in their first two years of teaching, and how the factors such as their prior learning experience, school curriculum and culture influence their identity formation. Varghese, Morgan, et al. (2005) presented the results of the three data-based empirical studies investigated ways of theorizing language teacher identity by employing the three different theoretical frameworks: Tajfel's (1978) social identity theory, Lave and Wenger's (1991) theory of situated learning, and Simon's (1995) concept of the image-text. They highlighted how these theories bring understanding to the different aspects of language teacher identity.

Researches on teachers' identity and teachers' professional identity are still underway in China. There have been some studies on teacher identity recently, for example, Li (2009) analyzed the factors influencing teacher identity; Ma (2005) researched into self-identity of college foreign language teachers; Yang (2007) studied minority teachers' identity; Wang (2002) investigated the present condition of study on minority nationality identity; Wang (2005) explored the problems and strategies of the Tibetan teachers' professional development at primary school. From the above review, we see that there is much literature about teacher identity in relation to primary school, middle school and university teachers as well as ethnic identity. However, there appears to be fewer researches on the foreign language teacher identity at university in minority areas in China. The present study is a case study focusing on Mongolian English teacher's identity, analyses what her identity is, how she perceives her identity and what factors influence her identity formation through interviews. The findings of the present study can be helpful for understanding university teachers' identity in the minority areas, factors influencing their perception of being university teachers at minority areas, and their identity formation. It has some implications especially for teacher education, teacher development policy, teacher professional development in the minority areas in China.

\section{Research methods}

\subsection{Participant}

Teacher $\mathrm{Wu}$ was born in a city with two million populations, among whom almost eighty percent is Han Chinese. Her parents are both Mongolian, her father is an expert on folklore, and her mother worked at university too. Her family keeps well the folk custom, and has the tradition of having Mongolian food, for example, eating milk products such as cheese, eating mutton and beef rather than pork, and drinking milk tea. Teacher Wu is at her thirties, with a master degree. She can speak very standard Mongolian, and she also can speak native-like Chinese. She began to learn English from A, B, C after she entered university. She has more than 10 years 
experience of teaching English to Mongolian students at one of the best universities in Inner Mongolia. She was married, has a very lovely daughter, who is Mongolian and Chinese bilingual, and learns some English at primary school; her husband is Mongolian, too. Teacher Wu was born in a Mongolian family and has Mongolian family of her own. She is a trilingual speaker and teaches English to Mongolian third language learners at university.

\subsection{Data collection method}

This is a pilot study and a part of the interview study investigating Mongolian English teachers' identity, their perceptions of themselves and factors influencing their identity formation. The semi-structured interview guide covers the following topics: language background, learning experiences; teaching and professional development; language use; the advantages and disadvantages of being minority English teachers at university, and the planning for future study and research, etc. The interview was transcribed and analyzed according to the themes emerged from the data.

\section{Results and Discussion}

\subsection{Teacher Wu's identity}

As a common sense, the way people speak and the language people use are all symbols of who they are or what identity they have (Wang Lin, 2009). In a word, language use can be a mirror to indicate people's identity. Therefore, in the following section, being a university English teacher in minority area, what identity teacher Wu has and how she perceives her identity are analyzed from the perspectives of the languages she uses at home, at working place and in her classroom teaching and the competences of the languages she speaks, which is believed to be influenced by living social context, her family background, her learning experiences and working contexts. Teacher Wu's identity is multifaceted because of her living and working in a multilingual society with different cultures, leading her to have particular social, cultural, ethnic, professional identities.

Teacher Wu is a Mongolian, and she speaks Mongolian a lot with her family members and friends; however, she seldom writes Mongolian and her writing ability of Mongolian is decreasing. She felt very pity for this. In order not to let the next generation to forget her own national language and customs, she sends her daughter to Mongolian primary school to learn Mongolian (Of course, she learns Chinese and English at the primary school). She stated the reason why she sent her daughter to the Mongolian primary school as follows: "It is easy for the Mongolian kids to learn Chinese since they listen to Chinese a lot; they play with their Chinese little friends and communicate in Chinese very often, even in the Mongolian primary school; however, if the kids were not sent to the Mongolian primary school, it is great difficult for the kids to learn Mongolian since they have little chance to listen to Mongolian and speak of it in their daily life." The above statements tell us the strong ethnic identity the teacher Wu has.

Teacher $\mathrm{Wu}$ is a fluent Chinese speaker. She lives and works in a society with a large population of Chinese, and she is quite familiar with the Chinese culture. However, she encounters some difficulties in her teaching. She stated that when I did some translation exercises from English to Chinese, sometimes I can't find the right words to use, and sometimes I am not confident enough for appropriateness of word use as well. She stated the reasons for using Chinese a lot in teaching Mongolian students instead of Mongolian, for example, there are few text materials developed in Mongolian; the Mongolian teachers learned English in Chinese and English, so it is convenient for them to teach in Chinese and English rather than in her mother tongue, Mongolian, which was not used very often in their learning; the Mongolian teachers uses Chinese a lot in her daily life, etc., just name a few.

Teacher Wu is a university English teacher, she often uses English in her teaching, and she has to understand the target language culture and help her students to be familiar with it. She mentioned several times that she is interested in culture study, and planned to conduct some comparative researches on cultures, especially cultures between Mongolian and English.

\subsection{Factors influencing teacher Wu's identity formation}

\subsubsection{Living environment}

Living environment is one of the factors having impact on teacher Wu's identity formation. She grew up in a big city. She stated "most neighbors of mine are Chinese, so when I was little, I had chances to contact with Chinese and I played with Chinese kids. I began to learn Chinese from third year at primary school, and I communicated with my classmates in Chinese a lot in my middle school days. When I entered university, all the courses were given in Chinese or the combination of Chinese and English except some common courses such as Marxism, etc. So she can speak very fluent Chinese. She believed and claimed that "among the three languages I speak, my 
Chinese is the best, since I very seldom use Mongolian after entering university as a student, and in my teaching as well. Therefore, my Mongolian ability is dropping compared to that in high school, especially in written expression". She was born in a Mongolian family and she speaks Mongolian a lot at home; however, her Chinese is better than any other languages she knows.

\subsubsection{Family background}

Family background is another factor influencing teacher Wu's identity formation. She was born in the Mongolian family, and she is a very fluent standard Mongolian speaker. She said "I often speak Mongolian at home with my family members and with my friends, especially with my daughter. I think that for Mongolian kids, they have the environment of learning and speaking Chinese, but if parents don't create opportunities for them to learn Mongolian, then it is difficult for them to learn Mongolian. From the above, we clearly know that teacher Wu has a complex identity. Being a Mongolian, she has a very strong sense of protecting and maintaining the mother tongue competence of the young generation, her daughter, but she uses Mongolian very seldom in her teaching, and her Chinese is better than her native language, Mongolian.

\subsubsection{Learning experience}

Learning experience is playing a crucial role in shaping teacher Wu's identity. She is a university English teacher; however her English learning experience began from university. She said "I chose to learn English from A, B and $C$ after coming to university because of my interest. All the major courses were taught by Chinese teachers in Chinese and English since there were no teachers who could teach in Mongolian at our department, and to me, pronunciation was easy, but grammar was difficult. I was worried when I couldn't understand what the teacher explained and I envied a lot Chinese students who shared the same dormitory with me, for they had learned English for six years when they came to university. If the similarities and differences among Mongolian, Chinese and English were pointed out to us when we were learning English, it should have been very helpful for us to master English. Some of the courses the Chinese students had were not provided for Mongolian students, so I felt my knowledge about the literature and culture was limited, which led to my lack of confidence in teaching sometimes. From the above statements, it is quite clear how the learning experiences influence teacher Wu's identity in her teaching profession.

\subsubsection{Working contexts}

After graduation, teacher $\mathrm{Wu}$ was assigned to teach at the university in which she spent four years' study life. There are altogether over 40 English teachers at her department, but almost over ninety percent are Chinese. Therefore, she has to use Chinese to communicate with them. She mainly taught Mongolian students English, most of the time she uses Chinese and English, sometimes she uses Mongolian to explain some grammar points, and she communicates with students in Mongolian after class. She explained the reason why she chose to be a teacher and the feelings and problems of being a minority university English teacher as follows. "I felt that being a university teacher was not very hard, with a little pressure. However, it has been changed now and Ifelt a lot of pressures for being a university teacher, such as the degree and burden of scientific research, etc. If there was no requirement for young teachers under 35 to get M.A degree from the school, I was thinking of planning to study for M.A. a few years later". She said "there would be a big trouble if I don't do any research studies for promotion". She also felt lack of confidence in working with Chinese English teachers in terms of culture knowledge because of the special learning experience, and written Chinese ability, as well as when dealing with translation in her teaching.

\section{Conclusion}

The present qualitative case study indicated that teacher Wu's identity is very complex, which is the product of social, cultural environments in which she lives and works. The findings show that teacher Wu's identity formation is influenced by many factors such as her living environment, family background and working contexts; however, among those factors, learning experiences seems to play very crucial role. Being a third language user and the learning experience of English have the responsibility for constructing teacher Wu's identity in her teaching profession in the minority area. The analysis of teacher Wu's perception of her identity and the factors influencing the formation of her identity may shed light on what identity university English teachers have in minority areas in China and what factors influence their formation of identity in their professional development in the socially and culturally different backgrounds in China, and what problems and dilemmas they have and what difficulties they encounter in their teaching as being minority English teachers at university, which appeals to the new understandings of the multifaceted identity and the current situations of university English teachers in minority areas in China. 


\section{References}

Beauchamp, Thomas. (2009). Understanding teacher identity: an overview of issues in the literature and implications for teacher education. Cambridge Journal of Education, 39(2), 175-189. http://dx.doi.org/10.1080/03057640902902252

Ericson, E. H. (1968). Identity, Youth and Crisis. New York: W.W. Norton and Company.

Flores, M. A. \& Day, C. (2006). Contexts which shape and reshape new teachers' identities: a multi-perspective study. Teaching and teacher education, 22: 219-232. http://dx.doi.org/10.1016/j.tate.2005.09.002

Franzak, Judith K. (2002). Developing a Teacher Identity: The Impact of Critical Friends Practice on the Student Teacher. English Education, 34(4), 258-279.

Fred A.J. Korthagen. (2004). In search of the essence of a good teacher: towards a more holistic approach in teacher education. Teaching and Teacher Education, 20: 77-97. http://dx.doi.org/10.1016/j.tate.2003.10.002

Johnson, K.E. (1992). Learning to teach, Instructional actions and decisions of pre-service ESL Teachers. TESOL Quarterly, 26, 507-535. http://dx.doi.org/10.2307/3587176

Li Maosen. (2009). An Analysis of Influencing Factors of Teacher Identity. Jiao yu fa zhan yan jiu, 44-47.

Ma Lifei. (2005). Research into self-identification of college foreign language teachers. Journal of Xin Yu College, 10(3).

Mead, G.J. (1934). Mind, self and Society. Chicago: University of Chicago Press.

Varghese, M., Morgan, B, Johnston, B. \& Johnson, K. A. (2005). Theorizing Language Teacher Identity: Three Perspectives and Beyond. Journal of Language, Identity, and Education, 4(1), 21-44. http://dx.doi.org/10.1207/s15327701jlie0401_2

Wang Lin. (2009). The exploration of The Professional Identity of Chinese English Teachers in The Field of TEFL. Zhong Guo Xiao Wai Jiao Yu, 12, 198-199.

Wang Xiaojun. (2005). The Research of the Problems and Tragedy about the Professional Development of The Tibetan Teachers--A Case Study in the Tibetan Primary School in Gannan Tibetan Autonomous Region. M.A Thesis.

Wang Yapeng. (2002). the Current State of Study on Minority Nationality identity. Xin Li Ke Xue Jin Zhan, 102-107. 